\title{
Sex difference in response to stress by lunar month: A pilot study of four years' crisis-call frequency Nicholas Kollerstrom ${ }^{* 1}$ and Beverly Steffert ${ }^{2}$
}

\author{
Address: ${ }^{1}$ Science and Technology Studies Department, University College London, Gower St, London WC1E 6BT, UK and ${ }^{2}$ Birkbeck College extra- \\ mural studies, Psychology Department, 26 Russell Square, London WC1E 7HX, UK \\ Email: Nicholas Kollerstrom* - nk@astro3.demon.co.uk; Beverly Steffert - DrSteffert@aol.com \\ * Corresponding author
}

Published: 10 December 2003

BMC Psychiatry 2003, 3:20

This article is available from: http://www.biomedcentral.com/I47I-244X/3/20

(c) 2003 Kollerstrom and Steffert; licensee BioMed Central Ltd. This is an Open Access article: verbatim copying and redistribution of this article are permitted in all media for any purpose, provided this notice is preserved along with the article's original URL.
Received: 23 June 2003

Accepted: 10 December 2003

\begin{abstract}
Background: This study is in response to the question of whether the moon can influence daily levels of stress.

Method: Four years of telephone-call frequency data were obtained from a single crisis-call centre. We used the method of lunar-day numbers I to 29 for analysis. We also tested the concept of 'strong moons' as occurring when the Sun was near to the lunar-node axis.

Results: An increase in calls was recorded from females and a decrease in calls by males during the new moon period, suggesting a sex difference in response, and there were proportionally more calls by males a fortnight later. A comparable swing in the male/female call-ratio on a weekly basis over Fridays and Saturdays was noted. Limitations of staffing at the call-centre prohibited comment on seasonal correlations.

Conclusion: Lunar-related studies of stress should endeavour to separate the data by sex or the effect can be lost. Distress-calls by women were more strongly linked to the lunar month than were those by men.
\end{abstract}

\section{Background}

Centuries of folklore attest to a relationship between the moon and human response, and both positive and negative-result surveys continue to appear. Of two recent UK studies, one reported a 'small but significant' increase in visits to doctors on days around full moons [1], while the other found a sharp peak in reports of persons bitten by animals during the same monthly period [2]. The general concept of increased stress at full moon or at certain full moons to account for these traditions was proposed by Lieber [3] and more recently reviewed by Dubrov [4]. If this concept has validity it should be evident in crisis-call frequencies.
Published investigations of possible lunar cycle influence on crisis call frequency since 1974 have been mainly American: Weiskot [5], De Voge \& Mikawa [6], Michelson, Wilson \& Michelson [7], Wilson \& Tobacyk [8], but also Canadian: Byrnes and Kelly [9] and Bickis, Kelly \& Byrnes [10]. Reviews of these by Rotton \& Kelly [11] (reviewed refs. 5,6 \& 7), Bickis et al. [10] (reviewed refs 8 \& 9), and Kelly, Rotton \& Culver [12] (reviewed refs. 9 \& 10), emphasised the negative nature of the results, i.e. that no significant peak in crisis calls could be linked to the lunar month. A Scottish study of hospital admissions following attempted suicide yielded a small amplitude waveform synchronised with the lunar quarters as was statistically insignificant [13], while a British study of attempted 


\section{ATTEMPTED SUICIDES, UK PLOTTED BY LUNAR MONTH}

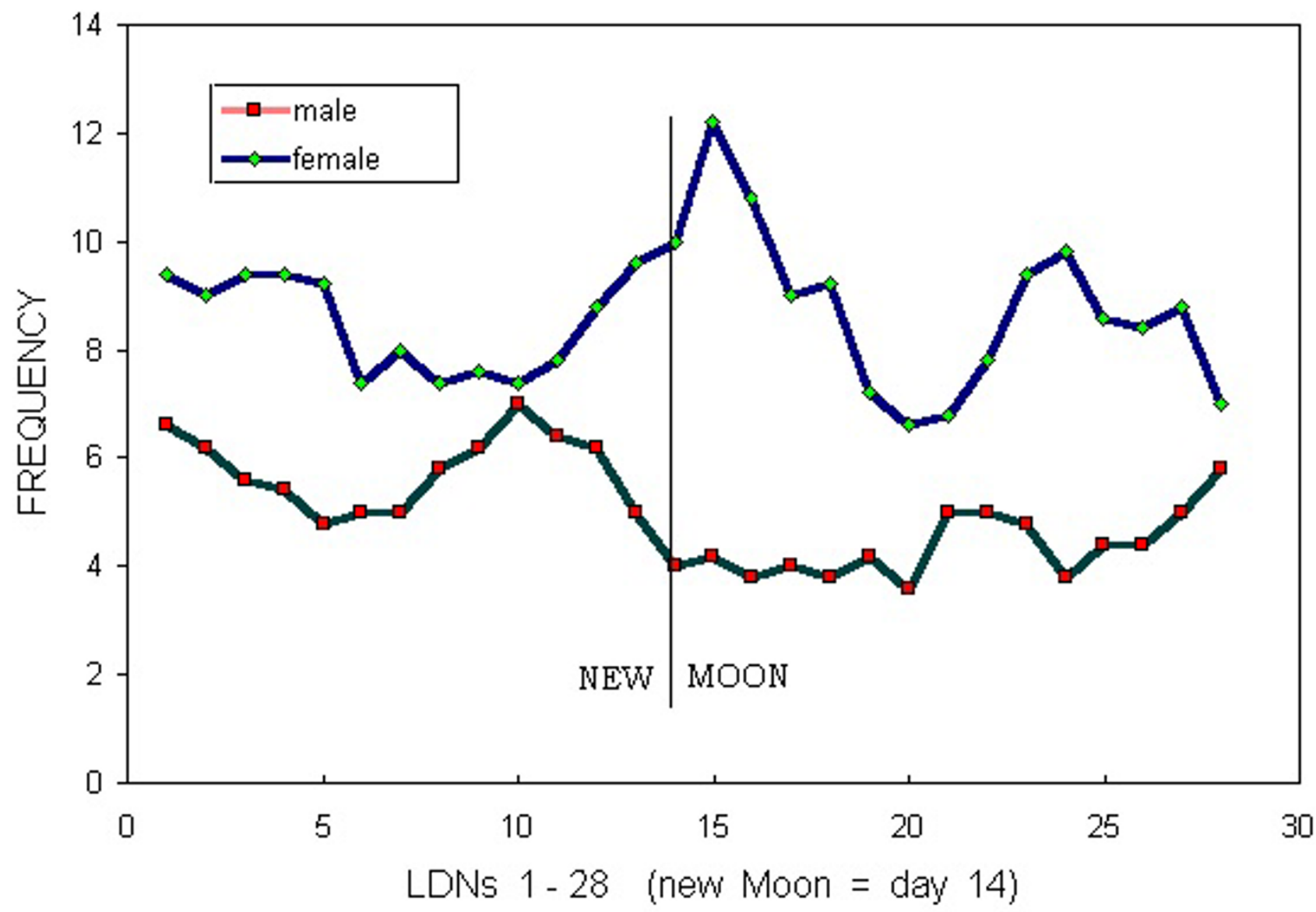

Figure I

Data from Matthew et al., (199I, Table I), showing 3-point moving averages of suicide attempts by men and women during 1989, grouped by lunar Days I to 28.

suicide claimed likewise to find no significant result [14]. Our enquiries into the continued availability of data showed that only the Canadian data-sets $[9,10]$ had been kept.

Only the Matthew et al. study of 1991 [14] gave data by sex. For 383 cases of attempted suicide from a hospital emergency department in Kent, UK, over a year these authors found "no evidence of increased sex-specific or overall attempted suicides in any of the lunar quarters" [15]. They gave totals over 28 lunar days, but how this was calculated given that the lunar month has 29.5 days* is unclear. Their data appeared to show a distinct trend: see
Fig. 1, in which data are smoothed by a 3-day moving average. The data was not graphed in this way in the Matthew et. al. study and so we have presented it here to bring out its trend: this figure shows a maximum sex-difference in attempts on days following the new moon, when suicide-attempts by females peaked.

The above-cited studies and reviews have tended to take for granted that a selenological study should focus on the full moon. Thus, the De Voge and Mikawa survey [6] showed a statistically significant excess of crisis calls over its 'new-moon' period, defined as the fourth lunar quarter, viz., the seven days prior to the new position, and then 
drew its negative conclusion. It seemed to us preferable to start by looking at frequency count per twenty-nine lunarday numbers.

\section{Gender-separation}

Our interpretation of the Matthew et. al. [14] data (Fig. 1) was supported by certain earlier findings, such as that by Ossenkamp and Ossenkamp [16] who reported a significant peak in frequency of self-poisoning by women only in Winnipeg, Canada, on days following the new moon, and an Australian survey on self-poisoning [17] from which the same conclusion was drawn. There were 2,215 hospital admissions involving self-poisoning over a sixyear period, during which over the new moon period $60 \%$ were for women, whereas at the full moon there were $45 \%$ women. The authors computed a mean 'degree of lunar illumination' over the times of men's self-poisoning, as having been 50.6\%, while for women that value was $47.5 \%$, indicating that women's self-poisoning was related more to the dark half of the lunar month. Further, an earlier Australian survey by Taylor and Diespacker [19] had yielded a statistically reliable relation of suicide attempts to the moon for women but not for men. These studies (reviewed by Dubrov [4]) suggested two things were desirable: a separation of data by sex and a fuller consideration of the days near the new moon rather than the full moon period. A focus upon this end of the lunar month has the notable advantage that the new moon, being invisible, is less likely to be associated with mediaderived expectations.

Further support for a procedure of sex-separation within this context comes from Frankenhauser [20] who showed how men and women respond differently to stress biochemically. She noted that men were more prone to react to stressful situations with raised blood pressure while women reacted with an increase in heart rate (Frankenhauser [21]). Also, a study of depressive cases admitted to hospital (diagnosed for manic-depressive psychosis and for psychotic and non-psychotic depressions) on days following 'geomagnetic storms' indicated a clear sex-difference in response [22]. This author claimed that increases in hospital admissions were triggered by bouts of severe geomagnetic activity over the decade 1976 to 1986 and that depressed men rather than women arrived in increased numbers in the wake of such events. Also the yearly distribution of these hospital admission cases varied by sex. These studies of stress and psychotic depression have implications for the peaking of crisis calls and endorse the notion that men's and women's call-frequencies should be evaluated separately.

\section{Probability}

A division of the lunar month into four "quarters" is inevitably problematic. Several of the prior studies $[5,6,15]$ divided the lunar month into quarters in which the 'full moon' sector signified the second quarter of the waxing moon from $90^{\circ}$ to $180^{\circ}$, measuring sun-moon angle. One would prefer these studies to have centred their divisions on the full and new positions, i.e., a $45^{\circ}$ rotation of the four boundaries specified above. These methods using Sun-moon angle would generate sectors without equal expected-frequencies.

The moon's elliptical orbit varies in angular velocity in relation to the Earth by more than $30 \%$ each month and peaks at perigee. The moon will spend various amounts of time in the different sectors, wherein the differing expected frequencies cannot be readily computed. It is preferable therefore for statistical study to be based on the method of lunar-day numbers, as this procedure takes account of the varying angular speed. From the beginning of each lunar-cycle days are counted 1 to 29 . Wishing to focus on the new moon, we started the counting with Day 1 as the first day for which the moon at noon was over $180^{\circ}$ from the sun, i.e. just past full, putting the new moon at day 15,16 , or 17 depending on where perigee was. That slight blurring of the new position is the drawback of this method, but the advantage is having days of the lunar month with equal expected frequencies. For this reason a statistical enquiry should be based on a division by time (sequence of days in the lunar month) rather than space (Sun-Moon angle).

\section{Astronomy}

A hypothesis involving the new moon concerns its passing between sun and earth, and one can more readily model a lunar effect on earthbound solar radiation at the new position than at the full. Lunar cycles having full and new positions close to the lunar nodes i.e. near the ecliptic are viewed as 'stronger' than those far away. The moon wanders $5^{\circ}$ on either side of the ecliptic (the plane of earth's orbit), so a new moon near its node (where eclipses occur) can more credibly affect earthbound solar radiation than one far away [23]. Geomagnetism varies with the lunar month [24], most notably on months whose full and new moons fall near to the ecliptic [25]. Best and Smith suggested that such geomagnetic perturbations mediated observed lunar effects and 'strong moons' were those close to the ecliptic at the full moon's position [26]. We checked this by splitting the data according to whether the sun was within $45^{\circ}$ of the lunar-node axis (Fig. 2).

\section{Methods}

Four years of daily crisis-call frequency data, 1995-98, from Milton Keynes, a town in central England, were obtained, and frequencies by sex were compared for the lunar month and days of the week. In contrast to earlier published surveys, this source had crisis-call frequencies 


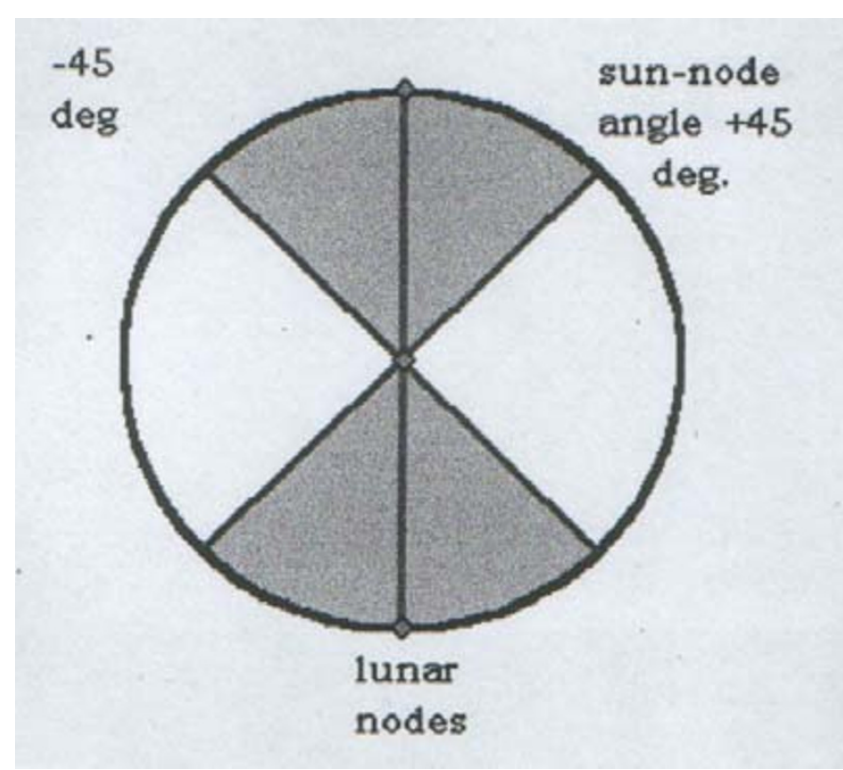

Figure 2

$45^{\circ}$ sectors of the ecliptic plane, on either side of the lunar nodes

available for men and women separately. A disadvantage was that the crisis calls were not all made in Milton Keynes, due to a national policy of re-routing the crisis calls to reflect staffing shortages, etc. between cities. This produced anomalies, e.g. Sunday is nationally the busiest day of the week for crisis calls, whereas in the present data this was the lowest of all days. This is a further reason as to why our enquiry deals with sex differences not total calls.

The data extended over 49 complete lunar cycles. To each date was assigned a 'lunar-day number' from 1 to 29 , where Day 1 was the first day following Full Moon, so calls during 49 days were summed within each lunar-day number. Alternate months contained a day ' 30 ' as were ignored, thereby discarding one-sixtieth of the data. Also, the data corresponding to the last two weeks were omitted to give an integral number of lunar months for the analysis. Altogether $2.7 \%$ of the primary data were thereby discarded, using in total 76,065 calls. For each date the arithmetic difference between calls by women and men was found. Would the sex-effect earlier reported in attempted suicides, of an excess of women over men at new moon periods, appear in crisis-call frequencies?

\section{Results \\ General remarks}

The call frequencies showed a steep increase which stabilised in the fourth year (Table 1). Frequency rates almost doubled over the four years, the increase being mainly from men. Of total calls, those by men showed a larger scatter than those by women: \pm 10.2 (36\% of the mean) as compared to \pm 6.5 calls per day ( $26 \%$ of the mean). Overall, there were $12 \%$ more calls by men than women.

\section{Lunar months}

We initially inspected the data as distributed by SunMoon angle. To each day of the four years a sun-moon angle $0-360^{\circ}$ was obtained, adding $180^{\circ}$ to centre it on New Moon. Arithmetic differences between women and men in daily total calls were sorted by that angle, and the total data-set smoothed using an arbitrary 250-point moving average. This covered $17 \%$ of the data-points: $250 /$ $1460=17 \%$, as is comparable to the spread of a 5-day mean, as $5 / 29=17 \%$. This analysis suggested (Fig. 3) a peak in calls by women centered on the new moon while a less definite peak in calls by men occurred over the full moons.

For each day of the 49 lunar cycles the sex-difference in call totals was computed, then to each of these lunar days was assigned a number 1 - 29. Daily difference-values were summed by these lunar-day numbers, shown in Fig. 4, converted to percentage deviations and then smoothed (as Fig. 1) by a three-point moving average. This shows a swing by sex of well over $10 \%$ during the lunar month. These lunar-day sums were then split into a 'new moon' group over the seven days 13 to 19 , and the remainder for Days 1 to 12 plus 20 to 29 . The former gave a mean score of daily call differences female-male of $-51 \pm 35$, while for the others the mean was $-178 \pm 58$ female-male calls per day. This relative increase in female calls over the new moon period was significant $(t=5.3)$.

We expressed these differences as percentages in Table 2. The percentage excess of calls by women over those by men were computed for these two divisions of the lunar month as defined, using the formula $\left(\mathrm{N}_{\mathrm{w}} / \mathrm{N}_{\mathrm{m}}-1\right) \times 100 \%$ where $\mathrm{N}_{\mathrm{m}}$ and $\mathrm{N}_{\mathrm{w}}$ are the call totals. This fourfold analysis showed a swing of $9 \%$ for the week centred on new moon as compared with the rest of the data. This is comparable to Fig. 4 which depicts the percent excess after adjustment to generate zero-centred deviations, by taking the formula as $\left(\mathrm{N}_{\mathrm{w}} / \mathrm{N}_{\mathrm{m}}-0.89\right) \times 100 \%$.

Given the steep year-by-year increase in these data, there is a case for correcting trends before the analysis. Accordingly, square root values were obtained of the separate daily totals for men and women over the four years [27] and two 29.5-day moving averages obtained and subtracted out [28]. The same analysis as above was then performed. This showed an excess of calls by women over those by men on the new moon lunar Days 13 to 19 , averaging $9.0 \pm 4.5$, while that for the others averaged $-2.8 \pm 6.0$ 


\section{FEMALE EXCESS OF C. CALLS CENTRED ON NEW MOON, 1995 - 8}

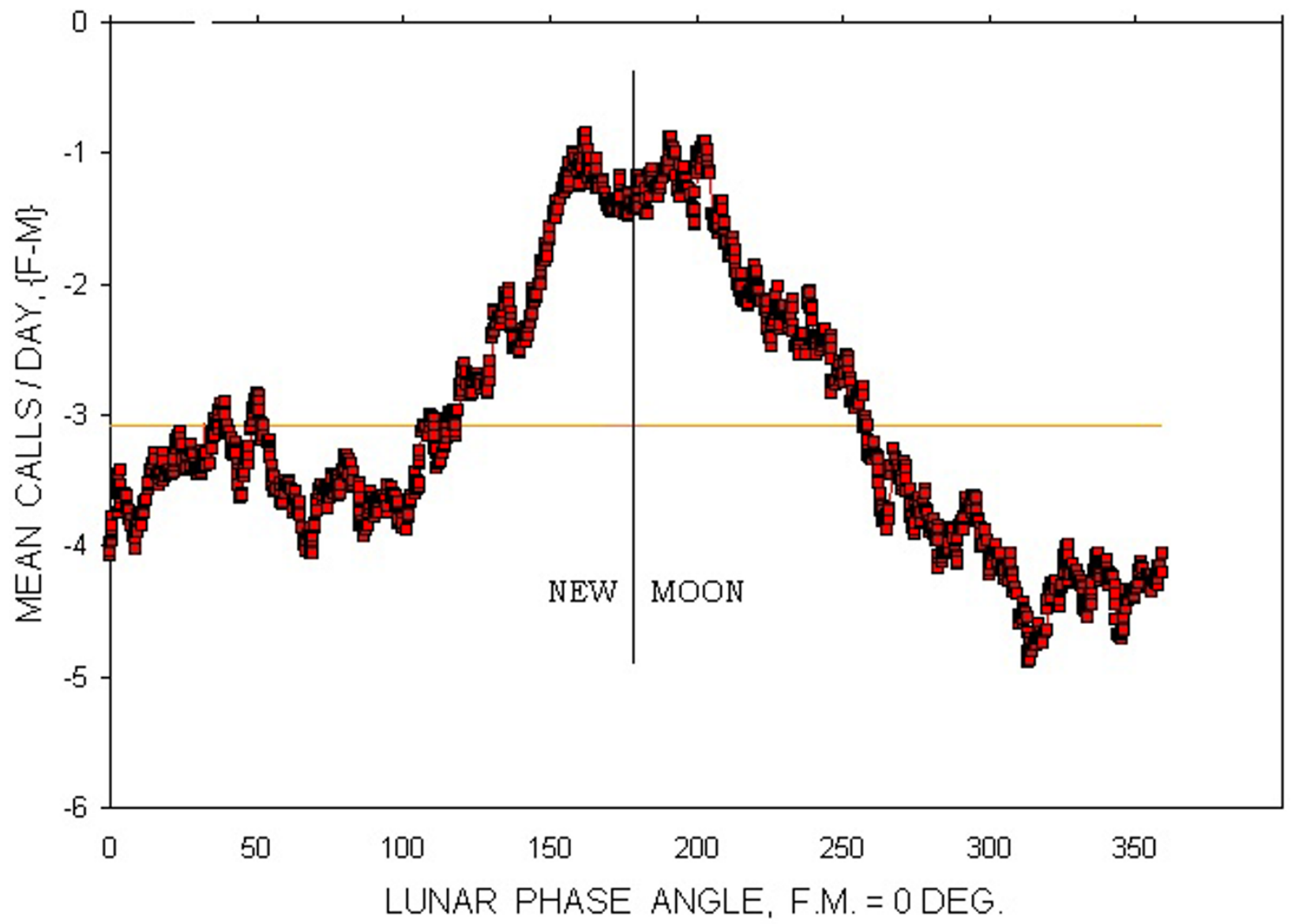

Figure 3

Differences (female less male) in daily crisis calls logged over 1995-98, sorted by their noon Sun-Moon angle (new moon = $180^{\circ}$ ), shown by a 250 -point moving average.

Table I: Yearly Mean of Total Daily Calls to Crisis-call Centre by Sex, with \% difference.

\begin{tabular}{lccccc}
\hline Group & & 1996 & Year & $\frac{1998}{26.1}$ & $\frac{1997}{25}$ \\
Women & $\frac{1995}{22.7}$ & $\frac{1996}{26.2}$ & 29.6 & 34.1 & 28.2 \\
Men & 19.8 & 29.4 & -15 & -26 & -11.5 \\
\% difference & +14 & -12 & & 29.8 & \\
\hline
\end{tabular}

$(t=4.6)$. The relative excess of calls by women over the new moon period remains comparable.
For comparison, the four years of data was grouped by its 48 calendar months and this showed only a $1.6 \%$ increase in the percentage of female calls in the latter half of the 


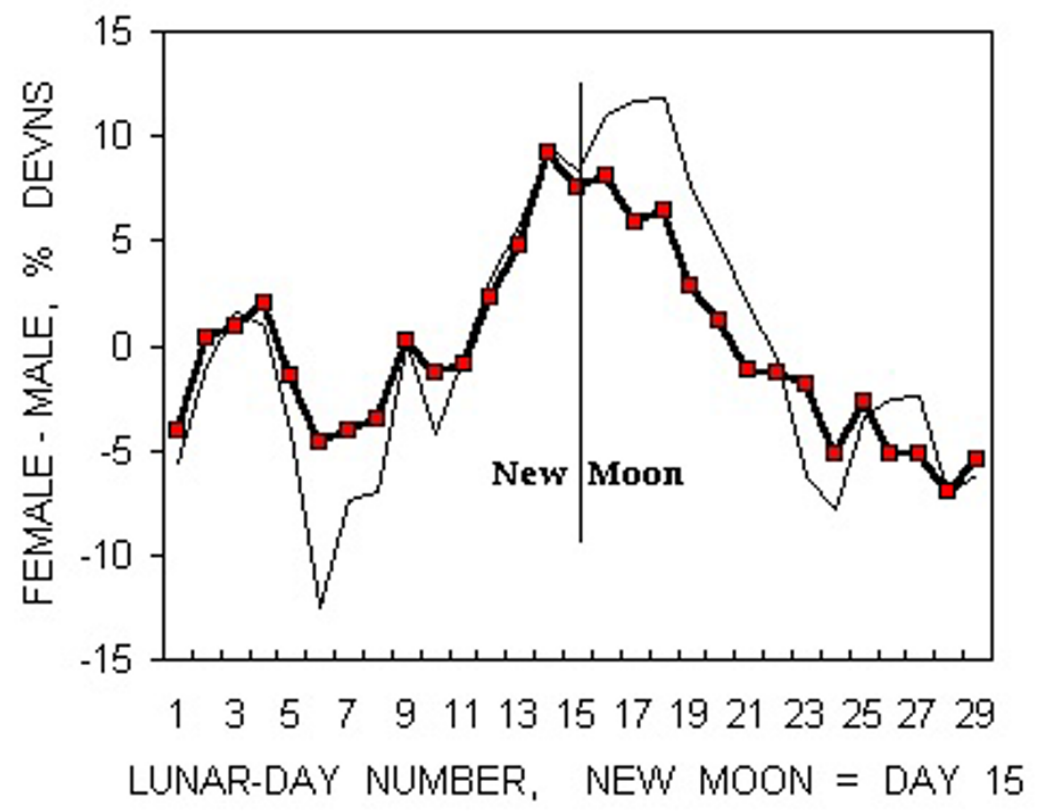

\section{Figure 4}

Differences (female less male) in daily calls over 1995-98, summed by lunar-day Numbers I - 29, and expressed as \% deviations from mean. The thin line was obtained by applying the same procedure to half of the data for 'strong moons' (see text).

Table 2: Total Number of Calls, with \% Differences, Divided (a) by lunar month, (b) Weekdays, and (c) New Moons near to Nodes.

\begin{tabular}{|c|c|c|c|}
\hline a) Lunar month & Male & Female & $\%$ female/male difference \\
\hline New moon, lunar Days I3-19 & 9,188 & 8,834 & -3.8 \\
\hline Others & 30,988 & 27,055 & -12.7 \\
\hline change in sex-ratio & & & $\overline{8.9}$ \\
\hline \multicolumn{4}{|l|}{ b) Days of week } \\
\hline Thursdays \& Fridays & 11,268 & 10,723 & -4.8 \\
\hline Saturdays \& Sundays & 12,073 & 10,058 & -16.7 \\
\hline change in sex-ratio & & & 11.9 \\
\hline \multicolumn{4}{|l|}{ c) 'Strong moons' } \\
\hline New moon, lunar Days $13-19$ & 4,319 & 4,345 & +0.6 \\
\hline Others & 14,965 & 13,196 & -11.8 \\
\hline change in sex-ratio & & & $\overline{12.4}$ \\
\hline
\end{tabular}

month as compared to the first; thus any trend in calendar months was an order of magnitude less than that obtained for the lunar months.

\section{Day of week}

The bar-chart (Fig. 5) shows the daily difference-values grouped by days of the week, expressed as zero-centred percentage deviations from the mean. A net excess of women's calls appears on Thursdays and Fridays, while 


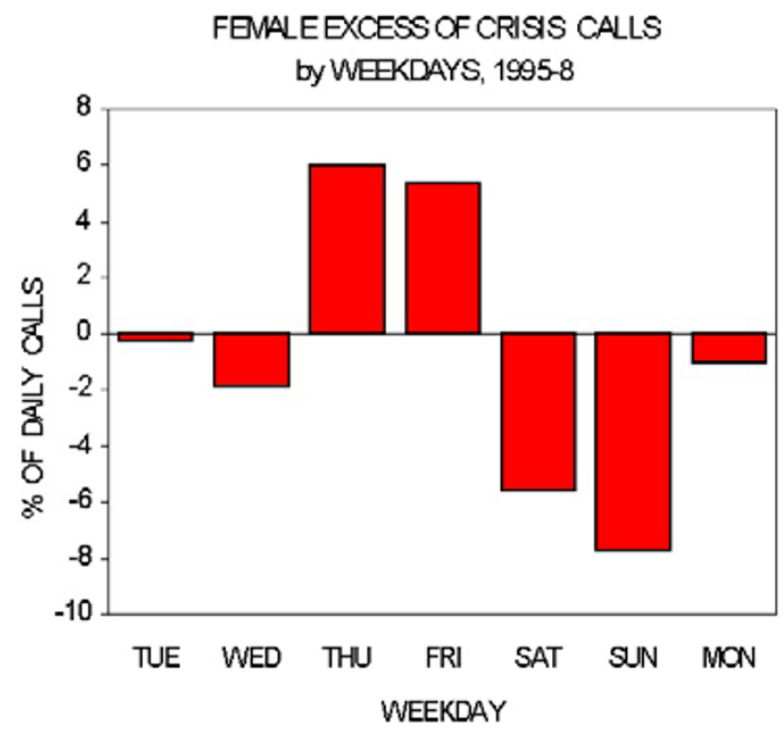

Figure 5

Differences (women less men) in daily calls over 1995-98 by days of week, expressed as percentage deviations from the mean.

men's calls peaked on Saturday and Sunday. Table 2 compares the Thursday + Friday excess with that over weekends. The swing in sex-ratio evident in this chart appears as comparable to that within the lunar-month cycle.

\section{Proximity of Sun-Lunar node}

The data were divided according to whether the Sun was within $45^{\circ}$ of the lunar nodes in celestial longitude, shown in Fig. 2. Twice a year the Sun traverses this axis, when the full and new moons fall close in latitude to the ecliptic and eclipses occur. These four years of data had eight such 'strong-moon' periods. The new moon quarter of the data (as defined) was then compared with the rest. The new moon difference-values \{women's less men's calls $\}$ averaged $3.7 \pm 26$ calls/day or $0.6 \%$ more calls by women, while the others averaged $-80.4 \pm 44$ calls/day $(t$ $=4.6$ ) or $12.5 \%$ more calls by men. The mean increase in call frequencies by women as compared to those of men during the new moon quarters was thus $12 \%$ (see Table 2).

The weekly deviations (Figure 5) were factored-out from the difference values, reducing the standard deviation of the $\{$ female - male $\}$ daily calls column by $4 \%$, to \pm 10.7 . Recomputing the results using this 'corrected' data-set did not improve the initial result, however, it did for the 'strong moons.' The graph (Fig. 3, thin line) shows this data-set.

\section{Discussion}

UK crisis-call frequency data, for which no analyses have hitherto been published, is valuable because it is separated by sex. The effect here discussed is unlinked to week or year, so does not merely reflect staffing, percentage of calls answered, etc. As confidentiality is required, no account can be taken of the length of the calls or for the length of time for which the phone lines are completely tied up. The analysis was not helped by a remarkably steep year-by-year increase in call frequencies. Conclusions must remain tentative, until further data become available. Further investigation of these effects could well be of assistance to persons answering the crisis-call phone lines, by predicting days when they would be more or less busy. A pronounced excess of weekend male calls presumably reflects a larger proportion of men being in employment during the week than women.

\section{Conclusions}

This pilot study has yielded potentially useful results using sex differences around the new moon, with a maximal excess of calls by women over those by men across the new moons around the eclipse seasons, as occur twice a year. The lunar nodes only moved some $70^{\circ}$ over the four years of the study, so the 'strong moons' of this survey are somewhat seasonally located, excluding the midsummer and Christmas periods, so one might choose to view the effect as seasonal, with strongest lunationcycles at spring and fall. More data are required to resolve this issue.

The female menstrual cycle has been shown to have its mean length indistinguishable from the synodic lunar month $[29,30]$, and women whose cycles average 28-30 days tend to have their menstrual period phase-linked to the lunar month $[31,4]$. Given that such a linkage has been reported, there may be nothing surprising about having a sex-differentiated stress-response to the lunar month. The linkage emerging from anthropological studies indicates that new moon was originally a time of menstruation [32], while the full was associated with ovulation, for that proportion of the female population who were holding the synchrony. Were that the case, the time of menstruation could have been experienced as a stressful time of the month for the women.

\section{Competing Interests}

None declared.

\section{Author contributorship}

The bulk of the analysis was done by Kollerstrom, with guidance and discussions with Steffert. 


\section{Note}

* They may have obtained this notion from a study published the previous year by Wilson and Tobacyk [8], which tested for 'the 28-day lunar cycle,' as well as a '30-day (monthly) cycle' in telephone crisis-call frequencies. The conclusions they reached are compromised by their use of the non-astronomical 28-day period. A 'twelve-year review' by Byrnes and Kelly [9] likewise discussed the (nonexistent) '28-day synodic lunar cycle' and the '30-day monthly cycle'. Not prior to their 1995 review [18] did these authors cite correctly the duration of the lunar month.

\section{References}

I. Neal RD, Colledge M: The effect of the full moon on general practice consultation rates. Family Practice 2000, I 7:472-474.

2. Bhattacharjee C, Bradley P, Smith M, Scally AJ, Wilson BJ: Do animals bite more during a full moon? Retrospective observational analysis. British Medical Journal 2000, 32 I:|56|-3.

3. Lieber A: The Lunar Effect. London, Corgi 1979.

4. Dubrov AP: Human biorhythms and the moon. New York, Nova Science publishers 1996.

5. Weiskott GN: Moon phases and telephone counselling calls. Psychological Reports 1974, 35:752-754.

6. De Voge SD, Mikawa JK: Moon phase and crisis calls: a spurious relationship. Psychological Reports 1977, 40:387-390.

7. Michelson L, Wilson J, Michelson J: Investigation of periodicity in crisis intervention calls over an eight year span. Psychological Reports 1979, 45:420-422

8. Wilson J II, Tobacyk J: Lunar phases and crisis centre telephone calls. Journal of Social Psychology 1990, I30:47-5I.

9. Byrnes G, Kelly IW: Crisis calls and lunar cycles: a twenty-year review. Psychological Reports 1992, 71:779-785.

10. Bickis M, Kelly IW, Byrnes G: Crisis calls and temporal and lunar variables: a comprehensive examination. The Journal of Psychology 1995, | 29:70|-7| I.

II. Rotton J, Kelly I: Much ado about the full moon: a meta-analysis of lunar-lunacy research. Psychological Bulletin 1985 97(2):286-306.

12. Kelly IW, Rotton J, Culver R: The moon was full and nothing happened: a review of studies of the moon and human behaviour and human belief. In: The Outer Edge Edited by: Nickell J, Karr B, Genoni J. New York, CSICOP; 1996: I7-34.

13. Rogers TM, Masterton G, McGuire R: Parasuicide and the lunar cycle. Psychological Medicine 1991, 2 I:393-397.

14. Matthew VM, Lindesay J, Shanmuganathan N, Eapen V: Attempted suicide and the lunar cycle. Psychological Reports 68:927-930.

15. Ibid ref. (1 4). :929.

16. Ossenkamp KP, Ossenkamp MD: Self-inflicted injuries and the Iunar cycle, a preliminary report. Journal of Interdisciplinary Cycles Research 1973, 4:337-348.

17. Buckley NA, Whyte IM, Dawson $\mathrm{AH}$ : There are days ... and moons: self-poisoning is not lunacy. Medical Journal of Australia 1993, I 59:786-789.

18. Op. cit. (1 0). :704

19. Taylor LJ, Diespacker D: Moon phases and suicide attempts in Australia. Psychological Reports 1972, 31:110.

20. Frankenhauser $M$ : Psychological perspectives on womens' health. In: A biopsychosocial approach to stress in women and men Edited by: Adesso VJ, Reddy DM. Philadelpia PA, Taylor \& Francis; 1994:39-56.

21. Frankenhauser M: The psychophysiology of workload, stress and health: comparison between the sexes. Annals of Behavioral Medicine 1991, 3:197-204.

22. Kay RW: Geomagnetic storms: association with incidence of depression as measured by hospital admission. British Journal of Psychiatry 1994, 164:403-409.

23. Bell B, Defouw R: Concerning a lunar modulation of geomagnetic activity. Journal of Geophysical Research 1964, 69:3 I69-3I74.

24. Best S: Behaviour patterns can be affected by the moon. Doctor (weekly) 1980, 25:32.
25. Bell B, Defouw R: Dependence of the lunar modulation of geomagnetic activity on the celestial latitude of the moon. Journal of Geophysical Research 1966, 71:951-957.

26. Smith C, Best S: Electromagnetic man. London, Dent \& Sons 1989

27. Hills M: Statistical methods: unit 3. Milton Keynes, UK, Open University Press 1986.

28. Gottman JM: Time-series analysis. London \& New York, Cambridge University Press 1981.

29. Treloar A, Boynton RE, Behn BG, Brown W: Variations of the human menstrual cycle through reproductive life. International Journal of Fertility 1967, I 2:77-126.

30. Vollman RF: The menstrual cycle. Major problems in obstetrics and gynecology Volume Monograph Series 7. Philadelphia, PA: Saunders; 1977.

31. Cutler W: Lunar and menstrual phase-locking. American Journal of Obstetrics \& Gynecology 1980, I 37:834-839.

32. Knight C: Blood relations, menstruation and the origins of culture. London, Cambridge University Press I991.

\section{Pre-publication history}

The pre-publication history for this paper can be accessed here:

http://www.biomedcentral.com/1471-244X/3/20/pre pub

Publish with Biomed Central and every scientist can read your work free of charge

"BioMed Central will be the most significant development for disseminating the results of biomedical research in our lifetime. "

Sir Paul Nurse, Cancer Research UK

Your research papers will be:

- available free of charge to the entire biomedical community

- peer reviewed and published immediately upon acceptance

- cited in PubMed and archived on PubMed Central

- yours - you keep the copyright 